\title{
Toward Errorless Condom Use: A Comparison of Two Courses to Improve Condom Use Skills
}

\author{
Dana F. Lindemann, ${ }^{1}$ Thomas A. Brigham, ${ }^{1,2}$ Colin R. Harbke, ${ }^{1}$ and Teresa Alexander $^{1}$
}

\begin{abstract}
Published online: Dec. 2, 2005
Traditionally, researchers have focused HIV/AIDS prevention efforts on increasing condom use, yet few researchers have assessed condom use skills. Because incorrect condom use may lead to condom failure, promoting condom use without ensuring participants have the skills necessary for correct condom use may lead to increased risk of exposure. This study compared the effects of two condom use courses on condom use skills. These courses were administered as part of a HIV/AIDS educational program for college students. Participants in the treatment groups $(n=179)$ attended either a limited, 1-Session, or extensive, 3-Session, condom use course, and an additional 108 participants served as a Control Group. Condom use skills increased among participants in both treatment groups; however, the greatest improvement was among those in the 3-Session Group. This finding supports use of the extensive, 3-Session course as a more effective means for improving condom use skills.
\end{abstract}

KEY WORDS: MOCUS; condom use skills; condom use failures; HIV/AIDS interventions.

\section{INTRODUCTION}

Correct and consistent condom use is the only effective method of protection against HIV/AIDS among those sexually active, and thus a common goal of intervention programs has been to promote consistent condom use (Langer et al., 1994). Although many researchers have successfully increased reported condom use following interventions, few have assessed condom use skills. For example, a recent synthesis of studies with adolescents showed that among the 56 interventions reviewed, only three (5\%) included an assessment of condom use skills (Johnson et al., 2003).

It is important to emphasize both consistent and correct condom use skills (Boldsen et al., 1992; Farris et al., 2003; Langer et al., 1994). Condoms only prevent HIV transmission when used effectively (Civic et al., 2002). By not ensuring that participants

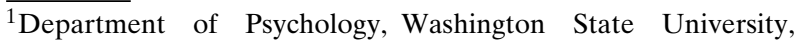
Pullman, WA.

${ }^{2}$ Correspondence should be directed to Thomas A. Brigham, Department of Psychology, Washington State University, Pullman, WA 99164-4820; e-mail: brigham@mail.wsu.edu.
}

have the skills necessary to use condoms correctly, programs may inadvertently increase incorrect and ineffective condom use. Incorrect condom use may lead to condom failures (i.e., breakage, slippage, or leakage) that increase risk of exposure (Crosby, 1998; Fishbein and Pequegnat, 2000). It has been demonstrated that condom users may not be aware of a failure until after ejaculation (Quirk et al., 1998). In addition, experience with condom failures may increase negative attitudes toward condoms (Kelly, 1995) and reduce the likelihood of future condom use (Norris and Ford, 1994; Richters et al., 1993). For example, Norris and Ford found that both negative experiences with condoms and negative attitudes toward condoms relate to decreased willingness to use condoms in the future and condom use during the last occasion of sexual intercourse.

Among studies where condom use failures were measured, $1 \%$ to $13 \%$ of condom uses failed (Messiah et al., 1997; Richters et al., 1995; Spruyt et al., 1998; Trussell et al., 1992; Warner et al., 1998), and $19 \%$ to $61 \%$ of participants reported having experienced a failure (Albert et al., 1991; Civic et al., 2002; Norris and Ford, 1994; Sanders et al., 2003). Although there is little research on the causes of condom use 
failures, Trussell et al. found that condom brand is not a predictor of failure. However, personal ability to use a condom correctly may be a consideration when weighing the costs and benefits of condom use (Catania et al., 1989) and user error may contribute to condom failures (Kelly, 1995). Therefore, it is possible that condom use failures result from user error and may be reduced by improving condom use skills.

There are two widely used methods for instructing consumers on correct condom use: written instructions on condom packaging and direct instruction as part of HIV/AIDS interventions. Condom use instructions provided on condom packaging are subject to space restrictions and typically include a few vaguely described steps accompanied by some illustrations. On the other hand, condom instructions provided as part of HIV/AIDS interventions are more complete. Frequently, researchers provide basic information about condoms, demonstrate how to correctly use condoms, and have participants practice correct condom use (see Belcher et al., 1998; Gibson and Lovelle-Drache, 1991; Kelly, 1995; Malow et al., 1994; Sorensen et al., 1991; St. Lawrence et al., 1999).

Many researchers who have evaluated HIV/AIDS interventions that incorporated condom use instruction reported success (Belcher et al., 1998; Eldridge et al., 1997). Often in these evaluations the researchers compared interventions based on different approaches, such as information only versus behavioral skills training (BST) interventions. Overall, this research has consistently demonstrated that BST produces more positive benefits than information only programs. Given the goal of skills training is to produce errorless condom use, research is needed to determine how much and what type of BST is required to achieve that goal. Therefore, the next step in developing the most effective condom use course is to evaluate the effects of differing BST interventions on condom use skills.

The purpose of this research was to evaluate the effects of two different condom use behavioral skills training courses on condom use skill level. The courses varied in time (1-session versus 3 -session) and content (limited versus extensive demonstrations and practice). Both conditions were administered as part of a 16-week HIV/AIDS educational program for college students. It was hypothesized that participants in both treatment groups would show an increase in condom use skills; however, it was expected that those receiving the extensive, 3-session course would show the great- est improvement and demonstrate more errorless performance.

\section{METHOD}

\section{Participants}

Participants were 287 undergraduates recruited from Introductory Psychology classes, residence halls, and Greek housing. Participants were $161 \mathrm{fe}-$ males and 120 males ( $\%$ unknown) who ranged from 18 to 56 years old $(M=19.85, S D=3.47)$. Participants were primarily white $(80 \%)$ and in their freshmen or sophomore year (71\%). Eighty-three percent of participants reported ever having sex, and $89 \%$ of those reported prior condom use.

Participants in the treatment groups $(N=179)$ were all enrolled in Psychology 106 (Psychology applied to daily living; Dealing with alcohol, friends and sex). These students were randomly assigned to one of the treatment groups (1-Session or 3Session). Control subjects $(N=108)$ were recruited from the department human subjects pool. Previous research comparing the two populations preintervention found no significant differences in frequency of sexual intercourse and the use of condoms (Peeler and Brigham, 2001). As a consequence, in terms of sexual behavior, the two populations appear to be equivalent.

\section{Measures and Materials}

The Measure of Observed Condom Use Skills (MOCUS; Lindemann and Brigham, 2003) was used to assess condom use skill level. The MOCUS consists of 7 dichotomous items and has demonstrated acceptable Guttman scalability (Reproducibility $=0.93$; Plus Percentage Ratio $=0.75$ ) and high inter-observer agreement (98\%). Each item on the MOCUS is a single, directly observable behavior that may prevent condom failure. With one exception, the MOCUS was administered according to Lindemann and Brigham. Based on the authors' recommendation, condom removal instructions were changed from "Please demonstrate how to handle the condom while pulling out" to read "Please demonstrate what to do with the condom while pulling out." The following condom application and removal steps were evaluated and scored using the MOCUS: 1) Without using teeth or fingernails, 
open condom package by tearing along edge; 2) Place condom right-side out on tip of penis; 3) Pinch tip of condom with two fingers; 4) Roll condom down the penis until reaching the base; 5) Hold condom at base of penis and remove the penis from the partner; 6) Pinch top of condom so that ejaculate is in the tip; 7) Holding the condom at the tip and base, carefully slide the condom off the penis.

\section{Setting}

Psychology 106, Psycology Applied to Daily Living: Dealing with Alcohol, Friends and Sex (Brigham, 2001; Brigham et al., 2002; Horn and Brigham, 1996) is a 16-week, 1-credit elective course offered to any university student. The class was taught by two peer instructors using a discussion and skills practice approach. Peer instructors were chosen from a group of advanced undergraduate students. Relevant experience, interview performance, schedule availability, and references were the primary criteria used to select peer instructors. Peer instructors attended an initial, 16-hour training session. During the semester, peer instructors met with their supervisors weekly to review material and prepare class for that week. Peer instructors used a manual (Donahoe et al., 2001) that outlined the discussion and activities for each class period.

\section{Experimental Design and Procedure}

A $2 \times 3$ mixed experimental design was employed, where time was the within-subjects factor, and level of treatment was the between-subjects factor. Participants in all groups were administered the MOCUS at pretesting (weeks 2 and 3 of Psychology 106 course) and posttesting (weeks 15 and 16 of the course). The average latency between pre- and post-testing was 98 days. Participants in the Control Group did not receive any condom use training, participants in the 1-Session Group received a limited, $50 \mathrm{~min}$ condom use course (week 12 of Psychology 106 course), and those in the 3-Session Group received an extensive, 150 min condom use course (three, 50 min sessions; weeks 11, 12, and 13 of Psychology 106 course). Participants were randomly assigned to treatment groups based on their Psychology 106 class section. Condom use course descriptions for each treatment condition are given in Table I.
Table I. Descriptions of the 1-Session and 3-Session Condom Use Courses

\begin{tabular}{|c|c|}
\hline 1-Session (Limite & 1) Condom Use Course \\
\hline Session 1: & \\
\hline Discussion & Introduction to condoms \\
\hline & Condom demonstration by peer instructors \\
\hline Skills Training & $\begin{array}{l}\text { Condom application practice (once, with } \\
\text { lights on) }\end{array}$ \\
\hline & Roleplay talking about condoms with partner \\
\hline & $\begin{array}{l}\text { Condom comparison activity ( } 3 \text { types of } \\
\text { condoms) }\end{array}$ \\
\hline Homework & $\begin{array}{l}\text { Purchase/pick-up free condoms and give one } \\
\text { to a friend }\end{array}$ \\
\hline & Assertive statements worksheet \\
\hline & $\begin{array}{l}\text { Placing condoms in your environment } \\
\text { worksheet }\end{array}$ \\
\hline 3-Session (Extens & ve) Condom Use Course \\
\hline Session 1: & \\
\hline Discussion & Introduction to condoms \\
\hline & Condom demonstration by peer instructors \\
\hline Skills Training & Roleplay talking about condoms with partner \\
\hline Homework & $\begin{array}{l}\text { Purchase/pick-up free condoms and give one } \\
\text { to a friend }\end{array}$ \\
\hline & Assertive statements worksheet \\
\hline & $\begin{array}{l}\text { Placing condoms in your environment } \\
\text { worksheet }\end{array}$ \\
\hline Session 2: & \\
\hline Discussion & Discuss homework \\
\hline & $\begin{array}{l}\text { Review/condom demonstration by peer } \\
\text { instructors }{ }^{a}\end{array}$ \\
\hline Skills Training & $\begin{array}{l}\text { Condom application practice (once each with } \\
\text { lights on, lights off }{ }^{a} \text {, and spinning in a chair } \\
\text { to simulate intoxication }{ }^{a} \text { ) }\end{array}$ \\
\hline & Condom application relay ${ }^{a}$ \\
\hline & $\begin{array}{l}\text { Roleplay teaching a friend how to use a } \\
\text { condom }^{a}\end{array}$ \\
\hline Homework & Teach a friend how to use a condom ${ }^{a}$ \\
\hline Session 3: & \\
\hline Discussion & Review homework $^{a}$ \\
\hline Skills Training & Written exam on steps to correct condom use ${ }^{a}$ \\
\hline & $\begin{array}{l}\text { Condom comparison activity ( } 3 \text { types of } \\
\text { condoms) }\end{array}$ \\
\hline
\end{tabular}

${ }^{a}$ Denotes activity or homework not included in the 1-Session (limited) condom use course.

At pre- and post-testing, participants were individually escorted to a private testing room, where a research associate administered the MOCUS. Participants were given a lubricated condom, wooden penile model, and the following instructions: "Please demonstrate how to apply a condom using this model." As the participant placed the condom on the model, the observer recorded if each MOCUS step for condom application was performed correctly. After the participant placed the condom on the model, the following instructions were given: 
Table II. Mean MOCUS Score and Percent Perfect Performance for Each Condition by Testing Session

\begin{tabular}{lccccc}
\hline & \multicolumn{2}{c}{ Pretest } & & \multicolumn{2}{c}{ Posttest $^{a}$} \\
\cline { 2 - 3 } Condition & $M(S D)$ & $\begin{array}{c}\text { Perfect } \\
\text { performance (\%) }\end{array}$ & & $M(S D)$ & $\begin{array}{c}\text { Perfect } \\
\text { performance (\%) }\end{array}$ \\
\hline Control $(n=108)$ & $4.27(1.58)$ & 8.5 & & $4.72(1.74)$ & 17.0 \\
1-Session (Limited; $n=90)$ & $4.01(1.39)$ & 6.9 & & $5.88(1.24)$ & 38.9 \\
3-Session (Extensive; & $4.12(1.79)$ & 5.8 & & $6.35(0.97)$ & 60.9 \\
$n=89)$ & & & & \\
\hline
\end{tabular}

${ }^{a}$ Attrition reduced posttest sample sizes to $n=94,72$, and 69 for the Control, 1-Session, and 3-Session Conditions, respectively.

\begin{abstract}
Now I would like you to rotate the model so it is parallel to the floor, as though the penis is still inside the partner. Please demonstrate what to do with the condom as the penis is removed from the partner. Then demonstrate how to remove the condom from the penile model.
\end{abstract}

As the participant demonstrated removal, the observer again recorded if each step was completed correctly. At the completion of posttesting, participants in all groups were provided a debriefing form that included the correct steps to condom usage.

\section{RESULTS}

Of the 287 participants who were administered the MOCUS at pretesting, 235 returned for posttesting (18\% attrition overall). Attrition was similar across the Control (13\%; $n=94$ remained), 1 Session $(20 \% ; n=72)$, and 3-Session Groups (22\%; $n=69)$. Attrition was slightly greater for the treatment groups because some students withdrew from Psychology 106 between pre- and post-testing.

At pretest, the percentage of participants who incorrectly performed each item on the MOCUS ranged from $7 \%$ to $65 \%$, and more than half of the participants incorrectly performed Items 3, 6 and 7. Item level performance was consistent such that the proportions of participants who incorrectly performed each item were similar across groups values ranged from 0.89 ( $n s ;$ Item 3) to 5.48 ( $n s ;$ Item 6). As displayed in Table II, mean pretest MOCUS scores and standard deviations were similar across groups. At both pre- and post-testing, MOCUS scores did not significantly differ between males and females, or between whites and non-whites.

A significant Group by Time interaction on mean MOCUS scores was found, $F(2,232)=27.33$, $p<0.01$ (see Table II). Planned contrasts showed that the 1-Session Group improved significantly more than the Control Group, $F(1,232)=23.80$, $p<0.01$, and the 3-Session Group improved significantly more than the 1-Session Group, $F(1$, $232)=4.65, p<0.05$. Because ANOVA may be inappropriate due to the MOCUS's ordinal scaling, analogous nonparametric comparisons were used to compare improvement (i.e., change scores) between the Control $(M=0.38, S D=1.76)$ and 1-Session Groups $(M=1.76, S D=1.66), U=4.94, p<0.01$, and between the 1-Session and 3-Session Groups $(M=2.42$, $S D=2.01), U=2.02, p<0.05$.

Chi-square test-of-difference of proportions were computed to compare the proportions of participants who scored perfectly on the MOCUS between treatment groups. At pretest, there were no differences between groups on the proportion of participants who scored 7 (i.e., 100\%) on the MOCUS, $\chi^{2}(2, N=287)=0.20$, ns. At posttest, however, the proportion of participantss who scored 7 on the MOCUS was greater among the 1-Session Group (39\%) than the Control Group (17\%), $\chi^{2}$ $(1, n=166)=10.01, p<0.01, O R=3.10$, and greater among the 3-Session Group (61\%) than the 1-Session Group, $\chi^{2}(1, n=141)=6.81, p<0.01, O R=2.44$ (see Table II).

\section{DISCUSSION}

There was a significant positive change on condom use skills among both treatment groups, and the 3-Session Group improved more than the 1-Session Group. Further, at posttest a greater proportion of participants in the 3-Session Group performed all steps on the MOCUS correctly compared to those from the 1-Session Group. Although both condom courses led to increased condom use skills, these data support use of the more extensive, 3-session condom use course as a more effective means to increase errorless condom use skills. 
These data also support the argument that it is important to promote both consistent and correct condom use (Boldsen et al., 1992; Farris et al., 2003; Langer et al., 1994). Although the vast majority of this sample reported prior condom use, at pretest less than $10 \%$ correctly performed all steps on the MOCUS. Because the MOCUS only includes steps that prevent breakage, slippage, or leakage, incorrectly performing even one item on the MOCUS may lead to increased likelihood of experiencing one of these failures. Thus, these data provide strong evidence that the majority of college students in our sample do not have all the skills necessary to use condoms correctly.

The percentage of errorless performance by the 3 -Session Group increased from less than $10 \%$ to $61 \%$ while that of the 1 -Session Group reached 39\%. This difference in performance is substantial and socially meaningful for those achieving errorless performance, but not sufficient. The 3-Session Group practiced putting a condom on a pseudo penis three times, took a written test over the steps for correct condom use, and completed a variety of other activities related to condom use. Given the goal of $100 \%$ errorless performance, we hoped to achieve a result of at least $80 \%$ of those students demonstrating errorless performance. One possible mistake in the design of the training was bunching all of the condom use skills training in a single class session. Perhaps a distributed practice strategy with practice in more than a single session would have produced more errorless performances (see Johnson et al., 2003). Alternatively, the sequence of instructional activities or some components in that sequence may need to be changed. Future research should systematically examine various combinations of instruction and practice. However, clearly from a public health perspective, the objective of condom use instruction needs to be mastery rather than improvement.

Because college students, while at high risk for STDs such as Chlamydia and HPV, are at much lower risk for HIV/AIDS, the implications of these findings for prevention work with higher risk populations (i.e., men who have sex with men and injection drug users) is unclear. Nonetheless, it is reasonable to predict that brief instruction will be no more effective with high-risk populations than with younger college students. Thus, the results pose a double challenge for prevention efforts. The first is to determine via direct assessment if current condom use training procedures are effective. Should they be found ineffective, the next challenge is to design more extensive training packages that higher risk populations will complete.

Younger ethnic minority women constitute another population at high risk for acquiring STDs including HIV/AIDS (CDC, 2003). These women certainly could benefit from mastering condom use skills but providing service to them is problematic. Logically, the place to contact these young women is the public schools and we have taught versions of the Psychology 106 class in alternative high schools in urban and suburban districts but our efforts to work in the mainstream public schools have been rejected. Realistically, the current social-cultural environment means that we need to develop methods for delivering condom use skill instruction to this and similar populations of young people who are increasing at risk (Levine, 2002).

A limitation of this study was that course attendance was not experimentally controlled. It is possible that individual participant's failure to attend all of the condom use sessions may have negatively affected the data for their respective group and, as a result, the data reported here may underestimate the efficacy of both treatments. Records of attendance provided by the Psychology 106 instructors indicated that 14 students $(16 \%)$ did not attend the single treatment session from the 1-Session Group. Among those in the 3-Session Group, 5 students $(6 \%)$ missed the first session, 7 (9\%) missed the second session, and $8(10 \%)$ missed the third session, and no students missed multiple sessions. Although the Psychology 106 instructors recorded attendance, to guarantee participants' confidentiality there was no way of linking a student's class attendance to his or her MOCUS scores. As a result we elected to analyze data from all participants for whom their assigned treatment was available to them. Nonetheless, student absences may have accounted for some of the differences in performance on the MOCUS. To provide the most accurate assessment of the effect of condom courses on participants' skill levels researchers should attempt to control for the negative effect of course absences in their methodology.

The participants in this study were students who volunteered for this course, yet $25 \%$ of those in the 3-Session Group missed one of the sessions. Although these absences may follow a typical pattern among college students, it raises questions about the feasibility of getting members from other, more high-risk groups to commit to extended training. Because we have evidence that longer training leads 
to greater errorless performance, it is important to establish similar programs specifically designed for members of these groups. Although it is likely the current pattern of results will be similar among other populations, it is important to test the efficacy of current programs targeting high-risk populations.

Although the extensive, 3-session course produced a high level of errorless condom use, we had hoped for even better results. More research is needed to find the most effective combination and order of components to ensure all participants acquire errorless condom use skills. In addition, further research is needed to assess the utility of the extensive course to other populations at risk of pathogen transmission in the event of condom failure (e.g., men who have sex with men or injection drug users). After incorporating the modifications necessary to insure an acceptable proportion of participants acquire errorless condom use skills, this version of the extensive multi-session course should be combined with an intervention that successfully promotes consistent condom use to achieve the public health goal of reducing the frequency of sexually transmitted diseases.

\section{ACKNOWLEDGMENTS}

The present research was completed in partial fulfillment for the degree of Doctor of Philosophy in Psychology. The authors thank Christian Lentz, Carol Young, Tiffani Maynard, and Emily Verbon for their greatly appreciated assistance in data collection, and Paul Bolls, Lisa Fournier, Jeff Joireman, and Craig Parks for their general support and guidance for this project.

\section{REFERENCES}

Albert, A. E., Hatcher, R. A., and Graves, W. (1991). Condom use and breakage among women in a municipal hospital family planning clinic. Contraception, 43, 167-176.

Belcher, L., Kalichman, S., Topping, M., Smith, S., Emshoff, J., Norris, F., and Nurss, J. (1998). A randomized trial of a brief HIV risk reduction counseling intervention for women. Journal of Consulting and Clinical Psychology, 66, 856861.

Boldsen, J. L., Jeune, B., and Madsen, P. C. (1992). Aspects of comfort and safety of condom: A study of two thousand intercourses among volunteer couples. Scandinavian Journal of Social Medicine, 20, 247-252.

Brigham, T. A. (2001). Psychology applied to daily living: Dealing with friends, alcohol, and sex (2nd ed.). Boston: Pearson Publishers.
Brigham, T. A., Donohoe, P., Gilbert, B., Thomas, N., Zemke, S., Koonce, D., and Horn, P. (2002). Psychology and AIDS education: Reducing high-risk sexual behavior. Behavior and Social Issues, 12, 10-18.

Catania, J. A., Dolcini, M. M., Coates, T. J., Kegeles, S. M., Greenblatt, R. M., Puckett, S., Corman, M., and Miller, J. (1989). Predictors of condom use and multiple partnered sex among sexually-active adolescent women: Implications for AIDSrelated health interventions. The Journal of Sex Research, 26, 514-524.

Centers for Disease Control, National Center for HIV, STD and TB Prevention, Divisions of HIV/AIDS prevention (2003). Cases of HIV infection and AIDS in the United States, (2002). HIV/AIDS Surveillance Report 14.

Civic, D., Scholes, D., Ichikawa, L., Grothaus, L., McBride, C. M., Yarnall, K. S., and Fish, L. (2002). Ineffective use of condoms among young women in managed care. AIDS Care, 14, 779788.

Crosby, R. A. (1998). Condom use as a dependent variable: Measurement issues relevant to HIV prevention programs. AIDS Education and Prevention, 10, 548-557.

Donahoe, P., Peeler, C., and Brigham, T. A. (2001). Teaching psychology applied to daily living: A peer instructor's guide. Boston: Pearson Publishers.

Eldridge, G. D., St. Lawrence, J. S., Little, C. E., Shelby, M. C., Brasfield, T. L., Service, J. W., and Sly, K. (1997). Evaluation of an HIV risk reduction intervention for women entering inpatient substance abuse treatment. AIDS Education and Prevention, 9 (Supplement A), 62-76.

Farris, C. A., Fenaughty, A. M., and Lindemann, D. F. (2003). A condom skill scale: Assessing condom skills among female drug users. Journal of Drug Education, 33, 217231.

Fishbein, M., and Pequegnat, W. (2000). Evaluating AIDS prevention interventions using behavioral and biological outcome measures. Sexually Transmitted Diseases, 27, 101-110.

Gibson, D. R., and Lovelle-Drache, J. (1991). Individual counseling. In J. L. Sorensen, L. A. Wermuth, D. R. Gibson, K. Choi, J. R. Guydish, and S. L. Batki (Eds.), Preventing AIDS in drug users and their sexual partners (pp. 117-129). New York: Guilford.

Horn, P., and Brigham, T. A. (1996). A self-management approach to reduce AIDS risk in sexually active heterosexual college students. Behavior and Social Issues, 6, 3-21.

Johnson, B. T., Carey, M. P., Marsh, K. L., Levin, K. D., and ScottSheldon, L. A. J. (2003). Interventions to reduce sexual risk for the Human Immunodeficieny Virus in adolescents, 19852000: A research synthesis. Archives of Pediatrics and Adolescent Medicine, 157, 381-388.

Kamb, M. L., Fishbein, M., Douglas, J. M., Rhodes, F., Rogers, J., Bolan, G., Zenilman, J., Hoxworth, T., Malotte, C. K., Iatesta, M., Kent, C., Lentz, A., Graziano, S., Byers, R. H., Peterman, T. A., for the project RESPECT study group: A randomized controlled trial. (1998). Efficacy of risk-reduction counseling to prevent human immunodeficiency virus and sexually transmitted diseases. Journal of the American Medical Association, 280, 1161-1167.

Kelly, J. A. (1995). Changing HIV risk behavior: A practical guide. New York: Guilford.

Langer, L. M., Zimmerman, R. S., and Cabral, R. J. (1994). Perceived versus actual condom skills among clients at sexuallytransmitted disease clinics. Public Health Reports, 109, 683687.

Levine, J. (2002). Harmful to Minors: The Perils of Protecting Children from Sex. Minneapolis: University of Minnesota Press.

Lindemann, D. F., and Brigham, T. A. (2003). A Guttman scale to assess condom use skills among college students. AIDS and Behavior, 7, 23-27. 
Malow, R. M., West, J. A., Corrigan, S. A., Pena, J. M., and Cunningham, S. C. (1994). Outcome of psychoeducation for HIV risk reduction. AIDS Education and Prevention, 6, 113125.

Messiah, A., Dart, T., Spencer, B. E., and Warszawski, J. (1997). Condom breakage and slippage during heterosexual intercourse: A French National Survey. American Journal of Public Health, 87, 421-424.

Norris, A. E., and Ford, K. (1994). Associations between condom experiences and beliefs, intentions, and use in a sample of urban, low-income, African-American and Hispanic youth. AIDS Education and Prevention, 6, 27-39.

Peeler, C., and Brigham, T. A. (2001). An analysis of the effects of a course designed to reduce the frequency of high risk sexual behavior and heavy drinking. Paper presented at the meeting of the Association for Behavior Analysis, New Orleans, LA.

Quirk, A., Rhodes, T., and Stimson, G. V. (1998). 'Unsafe protected sex': Qualitative insights on measures of sexual risk. AIDS Care, 10, 105-114.

Richters, J., Donovan, B., and Gerofi, J. (1993). How often do condoms break or slip off in use? International Journal of STD and AIDS, 4, 90-94.

Richters, J., Gerofi, J., and Donovan, B. (1995). Why do condoms break or slip off in use? An exploratory study. International Journal of STD and AIDS, 6, 11-18.
Sanders, S. A., Graham, C. A., Yarber, W. L., and Crosby, R. A. (2003). Condom use errors and problems among young women who put condoms on their male partners. Journal of American Medical Womens Association, 58, 95-98.

Sorensen, J. L., London, J., and Morales, E. (1991). Group counseling to prevent AIDS. In J. L. Sorensen, L. A. Wermuth, D. R. Gibson, K. Choi, J. R. Guydish, and S. L. Batki (Eds.), Preventing AIDS in drug users and their sexual partners (pp. 99-115). New York: Guilford.

Spruyt, A., Steiner, M. J., Joanis, C., Glover, L. H., Piedrahita, C., Alvarado, G., Ramos, R., Maglaya, C., and Cordero, M. (1998). Identifying condom users at risk for breakage and slippage: Findings from three international sites. American Journal of Public Health, 88, 239-244.

St. Lawrence, J. S., Crosby, R. A., Belcher, L., Yazdani, N., and Brasfeld, T. L. (1999). Sexual risk reduction and anger management interventions for incarcerated male adolescents: A randomized controlled trial of two interventions. Journal of Sex Education and Therapy, 24, 9-17.

Trussell, J., Warner, D. L., and Hatcher, R. A. (1992). Condom slippage and breakage rates. Family Planning Perspectives, 24, 20-23.

Warner, L., Clay-Warner, J., Boles, J., and Williamson, J. (1998). Assessing condom use practices: Implications for evaluating method and user effectiveness. Sexually Transmitted Diseases, $25,273-277$. 